\title{
Cardiopulmonary Exercise Testing in Repaired Tetralogy of Fallot: Multiparametric Overview and Correlation with Cardiac Magnetic Resonance and Physical Activity Level
}

\author{
Benedetta Leonardi ${ }^{1}$, Federica Gentili ${ }^{2}$, Marco Alfonso Perrone ${ }^{1,3}$, , Fabrizio Sollazzo $^{4}$, Lucia Cocomello ${ }^{5}$, \\ Stefani Silva Kikina ${ }^{4}$ (D), Rachel M. Wald ${ }^{6}$, Vincenzo Palmieri ${ }^{4}$, Aurelio Secinaro ${ }^{7}$, Maria Giulia Gagliardi ${ }^{1}$, \\ Attilio Parisi ${ }^{8}$, Attilio Turchetta ${ }^{1}$, Lorenzo Galletti ${ }^{1}$, Massimiliano Bianco ${ }^{4,+}$ (D) and Fabrizio Drago ${ }^{1,+}$ (D)
}

check for

updates

Citation: Leonardi, B.; Gentili, F.;

Perrone, M.A.; Sollazzo, F.;

Cocomello, L.; Silva Kikina, S.; Wald,

R.M.; Palmieri, V.; Secinaro, A.;

Gagliardi, M.G.; et al.

Cardiopulmonary Exercise Testing in

Repaired Tetralogy of Fallot:

Multiparametric Overview and

Correlation with Cardiac Magnetic

Resonance and Physical Activity

Level. J. Cardiovasc. Dev. Dis. 2022, 9,

26. https://doi.org/10.3390/

jcdd 9010026

Academic Editor: Giuseppe

Caminiti

Received: 6 December 2021

Accepted: 10 January 2022

Published: 13 January 2022

Publisher's Note: MDPI stays neutral with regard to jurisdictional claims in published maps and institutional affiliations.

Copyright: (c) 2022 by the authors. Licensee MDPI, Basel, Switzerland. This article is an open access article distributed under the terms and conditions of the Creative Commons Attribution (CC BY) license (https:// creativecommons.org/licenses/by/ $4.0 /)$
1 Department of Cardiology and Cardiac Surgery, Bambino Gesù Children's Hospital IRCCS, 00165 Rome, Italy; benedetta.leonardi@opbg.net (B.L.); mgiulia.gagliardi@opbg.net (M.G.G.); attilio.turchetta@opbg.net (A.T.); lorenzo.galletti@opbg.net (L.G.); fabrizio.drago@opbg.net (F.D.)

2 Department of Sport Medicine, Bambino Gesù Children's Hospital IRCCS, 00165 Rome, Italy; federica.gentili@opbg.net

3 Department of Cardiology and University Sports Centre, University of Rome Tor Vergata, 00133 Rome, Italy

4 Unità Operativa Complessa di Medicina dello Sport e Rieducazione Funzionale, Fondazione Policlinico Universitario Agostino Gemelli IRCCS, Università Cattolica del Sacro Cuore, 00168 Rome, Italy; fabriziosollazzo.md@gmail.com (F.S.); stefanisilva.kikina01@icatt.it (S.S.K.); vincenzo.palmieri@unicatt.it (V.P.); massimiliano.bianco@policlinicogemelli.it (M.B.)

$5 \quad$ Bristol Heart Institute, University of Bristol, Bristol BS2 8HW, UK; nn18747@bristol.ac.uk

6 Peter Munk Cardiac Centre and Joint Department of Medical Imaging, University Health Network, University of Toronto, Toronto, ON M5S 1A1, Canada; rachel.wald@uhn.ca

7 Advanced Cardiothoracic Imaging Unit, Department of Imaging, Bambino Gesù Children's Hospital IRCCS, 00165 Rome, Italy; aurelio.secinaro@opbg.net

8 Department of Movement, Human and Health Science, University of Rome Foro Italico, 00135 Rome, Italy; attilio.parisi@uniroma4.it

* Correspondence: marcoalfonso.perrone@opbg.net

+ These authors contributed equally to this work.

\begin{abstract}
Patients with repaired Tetralogy of Fallot (rToF) typically report having preserved subjective exercise tolerance. Chronic pulmonary regurgitation (PR) with varying degrees of right ventricular (RV) dilation as assessed by cardiac magnetic resonance imaging (MRI) is prevalent in rToF and may contribute to clinical compromise. Cardiopulmonary exercise testing (CPET) provides an objective assessment of functional capacity, and the International Physical Activity Questionnaire (IPAQ) can provide additional data on physical activity (PA) achieved. Our aim was to assess the association between CPET values, IPAQ measures, and MRI parameters. All rToF patients who had both an MRI and CPET performed within one year between March 2019 and June 2021 were selected. Clinical data were extracted from electronic records (including demographic, surgical history, New York Heart Association (NYHA) functional class, QRS duration, arrhythmia, MRI parameters, and CPET data). PA level, based on the IPAQ, was assessed at the time of CPET. Eighty-four patients (22.8 \pm 8.4 years) showed a reduction in exercise capacity (median peak $\mathrm{VO}_{2} 30 \mathrm{~mL} / \mathrm{kg} / \mathrm{min}$ (range 25-33); median percent predicted peak $\mathrm{VO}_{2} 68 \%$ (range 61-78)). Peak $\mathrm{VO}_{2}$, correlated with biventricular stroke volumes (RVSV: $\beta=6.11$ (95\%CI, 2.38 to 9.85), $p=0.002$; LVSV: $\beta=15.69$ (95\% CI 10.16 to 21.21), $p<0.0001)$ and LVEDVi ( $\beta=8.74$ (95\%CI, 0.66 to 16.83), $p=0.04)$ on multivariate analysis adjusted for age, gender, and PA level. Other parameters which correlated with stroke volumes included oxygen uptake efficiency slope (OUES) (RVSV: $\beta=6.88$ (95\% CI, 1.93 to 11.84), $p=0.008$; LVSV: $\beta=17.86$ (95\% CI 10.31 to 25.42$), p<0.0001$ ) and peak $\mathrm{O}_{2}$ pulse (RVSV: $\beta=0.03$ (95\%CI, 0.01 to 0.05 ), $p=0.007$; LVSV: $\beta=0.08$ (95\% CI 0.05 to 0.11$), p<0.0001)$. On multivariate analysis adjusted for age and gender, PA level correlated significantly with peak $\mathrm{VO}_{2} / \mathrm{kg}(\beta=0.02,95 \% \mathrm{CI} 0.003$ to 0.04 ; $p=0.019$ ). We observed a reduction in objective exercise tolerance in rToF patients. Biventricular stroke volumes and LVEDVi were associated with peak $\mathrm{VO}_{2}$ irrespective of RV size. OUES and peak $\mathrm{O}_{2}$ pulse were also associated with biventricular stroke volumes. While PA level was associated with peak $\mathrm{VO}_{2}$, the incremental value of this parameter should be the focus of future studies.
\end{abstract}


Keywords: Tetralogy of Fallot; cardiopulmonary exercise testing; physical activity; cardiac magnetic resonance; exercise capacity; pulmonary valve

\section{Introduction}

Tetralogy of Fallot (ToF) is the most common form of cyanotic congenital heart disease (CHD) and accounts for $10 \%$ of all forms of CHD [1-3]. Surgical repair of Tetralogy of Fallot (rToF) has significantly improved long-term survival. However, this repair can result in pulmonary regurgitation (PR) and right ventricular (RV) volume overload, which has been associated with RV dilation, RV dysfunction, symptomatic heart failure, ventricular arrhythmia and sudden death [4-8]. In contrast, other patients can have predominantly pressure overload due to residual right ventricular outflow tract obstruction (RVOTO) [9]. Consequently, the exercise capacity of many patients can worsen over time following subjective assessment [10], despite reporting preserved subjective exercise tolerance.

Cardiopulmonary exercise testing (CPET) has been demonstrated to be a valuable tool in the objective assessment of exercise tolerance by measuring the peak oxygen consumption (peak $\mathrm{VO}_{2}$ ) [11,12]. Thus, it has been advocated as a diagnostic and prognostic tool to recognize early signs of clinical deterioration in most CHD patients [12], including the rToF population [13-15]. Most patients report no limitations in day-to-day activities. Therefore, in asymptomatic patients, CPET could give objective information about the function of the heart, lungs, and muscles and be a useful tool for helping to choose the optimal timing for pulmonary valve replacement (PVR) in the presence of significant RV dilation with or without dysfunction. Babu-Narayan et al. showed that in rToF patients undergoing PVR, preoperative oxygen uptake was indeed predictive of early postoperative mortality [16]. However, the relationship between RV dilatation and/or dysfunction and some CPET parameters is still poorly understood $[17,18]$. In addition, its potential usefulness as a tool for risk stratification and patient selection in asymptomatic adolescents and adults with rToF remains unclear. CPET parameters can be affected by age, gender, body size, and physical activity, especially in children and young adults [19-21]. In fact, a borderline peak $\mathrm{VO}_{2}$ measurement may be difficult to interpret in sedentary patients and may not be a reflection of the underlying cardiorespiratory disease [22,23]. Within this framework, an accurate estimation of the level of physical activity is also essential in rToF patients to define its impact not only on exercise capacity but also on other CPET parameters like ventilatory efficiency (VE/ $/ \mathrm{VCO}_{2}$ slope) and oxygen uptake efficiency slope (OUES). These parameters have recently emerged [21], in addition to oxygen consumption, but the clinical utility of these values in the rToF population remains uncertain. Therefore, our aims were to (1) explore the relationship between CPET and MRI parameters in our cohort of rToF patients in order to understand if the RV dilatation and/or dysfunction could affect their functional capacity; (2) assess the $\mathrm{VE} / \mathrm{VCO}_{2}$ slope and OUES to determine the incremental value of these measurements in the rToF population; (3) identify the mean level of physical activity in the rToF population and consequently explore the correlation between physical activity level and CPET parameters.

\section{Materials and Methods}

\subsection{Patient Population}

We performed a retrospective review of all collaborative rToF patients older than 12 years who underwent both MRI and CPET at Bambino Gesù Children's Hospital, Rome, between March 2019 and June 2021. We selected 84 patients who performed contemporary CMR and CPET (within 12 months) and did not present a significant decline in clinical status (NYHA functional class). We excluded patients with a previous PVR and patients with residual shunts. Finally, we included the last clinical evaluation of each patient with the record of all adverse clinical events. All-cause mortality, aborted cardiac arrest, documented ventricular fibrillation (VF), sustained ventricular tachycardia (VT) lasting $30 \mathrm{~s}$ 
or longer, atrial arrhythmias (atrial fibrillation, atrial flutter, supraventricular tachycardia), non-sustained VT (NSVT), and/or pacemaker implantation were recorded at follow-up. RV hypertension was evaluated by the tricuspid regurgitation gradient using continuouswave Doppler ultrasound by echocardiography. Precisely, we measured the velocity of the regurgitant jet and calculated the peak pressure gradient between the right ventricle and right atrium by applying the Bernoulli equation. The study was approved by the Ethics Committee of the Bambino Gesù Children's Hospital, IRCCS (Prot. Number 341/2015), and all subjects gave written informed consent. The study was conducted in accordance with the Declaration of Helsinki.

\subsection{CPET Protocol}

Informed consent was obtained from the parents or the patient prior to the test. Spirometry was performed prior to each CPET. All patients performed a symptom-limited CPET on a treadmill, undergoing the incremental Bruce protocol. Breath-by-breath expired gas analysis was performed according to international guidelines and recommendations [24,25]. Predicted normal peakVO $\mathrm{VO}_{2}$ values for adult and pediatric patients were derived from the Hansen and Wasserman [26] and Cooper [27] formulas, respectively. Twelve-lead electrocardiographic monitoring was maintained throughout the test. Blood pressure and pulse oximetry were recorded every 2-3 min and at peak exercise. For the CPET data, we focused on all the parameters which are usually collected and assessed these variables using equations that account for age, gender, body height, body weight, and testing modality [26-28].

\subsection{MRI Imaging}

MRI examinations were performed on a $1.5 \mathrm{~T}$ scanner (AERA $1.5 \mathrm{~T}$ scanner, Siemens, Erlangen, Germany), in accordance with previously published imaging protocols [29]. These included multiple sequences to assess anatomy, cine steady-state free precession sequences for volume and function assessment and phase-contrast imaging to measure flow in the pulmonary valve, aortic valve, and in both pulmonary arteries.

\subsection{Image Analysis}

The acquired data were analyzed offline by a single reader on a separate workstation using a cardiac post-processing software (Viewforum, Philips Medical, Best, The Netherlands, CMR42, Circle Cardiovascular Imaging, Calgary, AB, Canada). Assessment of LV and RV volumes was performed by manual segmentation of the endocardial border of both ventricles on short-axis cine images at end-diastole and end-systole, then calculated using the method of discs [30]. Trabeculations and papillary muscles were considered as part of the blood pool [31]. The ejection fraction (EF) was calculated from the measured volumes. All volumes were indexed to body surface area (BSA), calculated using the formula of DuBois et al. (BSA $\left(\mathrm{m}^{2}\right)=0.007184 \times$ Height $(\mathrm{cm}) 0.725 \times$ Weight $\left.(\mathrm{kg}) 0.425\right)$ with reference to published normal values [32]. Blood flow was calculated from phasecontrast images using a semiautomatic edge-detection algorithm with operator correction. The regurgitant fraction was calculated as retrograde flow divided by the anterograde flow. Pulmonary regurgitation was considered mild if the regurgitant fraction was $<20 \%$, moderate between 20 and 40\%, and severe $>40 \%$ [33]. Pulmonary arteries/RV outflow tract stenosis was diagnosed when two or more of the following MRI criteria were fulfilled (in addition to RV pressure $\geq 45 \mathrm{mmHg}$ on echocardiography): (1) flow velocity across the RV outflow tract or a branch pulmonary artery $\geq 3 \mathrm{~m} / \mathrm{sec}$; (2) abnormal pulmonary artery size based on BSA-adjusted z-scores for the right pulmonary artery (RPA), and left pulmonary artery (LPA); (3) asymmetric blood flow distribution to lung fields (RPA $<40 \%$; LPA $<20 \%$ ) [34]. The threshold for systolic dysfunction was RVEF $\leq 51 \%$ and LVEF $\leq 55 \%$, based on Kawel-Boehm et al.'s article [32]. 


\subsection{Physical Activity Evaluation}

Physical activity was assessed through the International Physical Activity Questionnaire (IPAQ) [35], which has already been evaluated in the CHD population [36]; IPAQ was administered to each participant before the CPET. The levels of physical activity were classified as "low/inactive", "moderate" and "vigorous".

\section{Statistical Analysis}

The descriptive statistics were expressed as the median and interquartile range (IQR) for continuous variables and as counts and percentages for categorical variables.

Linear regression was carried out to investigate the relationship between CPET parameters and cardiac MRI parameters. Two models were fitted for each outcome: the first model was unadjusted, and the second was adjusted for specified confounders. Linear regression was carried out to investigate the relationship between IPAQ (considered a continuous variable ranging from 0 to 2), CPET, and cardiac MRI parameters. Two models were fitted for each outcome: the first model was unadjusted, and the second model was adjusted for specified confounders. Confounders are defined as any factors that are known or plausible causes of the exposure and outcome. We agreed that the following factors could plausibly influence cardiac MRI parameters and CPET outcomes: sex, age at CPET, and level of physical activity. Sex and age at CPET were considered to be confounders of the IPAQ. The normal distribution and homoscedasticity of residuals were checked with Normal Q-Q and Spread-Location plot, respectively. We also checked if there were cases outside of the Cook's distance. Complete case analysis was performed. All statistical analyses were performed using the R Statistical Software, version 3.2.3 (R Foundation for Statistical Computing, Vienna, Austria).

\section{Results}

\subsection{Participant Characteristics}

Eighty-four consecutive patients were included in this study ( $51 \%$ male). The transannular patch was the most frequent repair $(67.5 \%)$. The other types of repair included monocusp valve reconstruction (13.3\%), infundibular patching (14.5\%), RV to pulmonary artery conduit $(3.6 \%)$, and finally, valvulotomy $(1.1 \%)$, which was performed in one patient. The median age at surgery was 9 months (IQR 5-16), whereas the median age at referral to our evaluation was 21.1 years (15.0-30.0). The echocardiographic evaluation revealed RV hypertension in 6 patients and normal RV pressure in the remaining. All demographic features are shown in Table 1.

Table 1. Characteristics of $84 \mathrm{rToF}$ patients. Data are expressed as median values and interquartile ranges for continuous variables and as counts and percentages for categorical variables.

\begin{tabular}{|c|c|c|}
\hline \multicolumn{3}{|c|}{ Overall $(N=84)$} \\
\hline \multirow{6}{*}{ Demographic features } & Male sex, n (\%) & $41(48.8 \%)$ \\
\hline & Age at repair (months) (median, IQR) & $13.4(0.0-87.0)$ \\
\hline & Age at CPET (yrs) (median, IQR) & $21.1(15.0-30.0)$ \\
\hline & Time between surgery and CPET (yrs) (median, IQR) & $20.2(10.2-28.9)$ \\
\hline & BSA $\left(\mathrm{m}^{2}\right)$ (median, IQR) & $1.7(1.1-2.2)$ \\
\hline & BMI (median, IQR) & $22.6(15.6-33.3)$ \\
\hline \multirow{14}{*}{ MRI parameters } & RVEDV (mL) (median, IQR) & $205.0(106.0-327.9)$ \\
\hline & RVEDVi (mL/m²) (median, IQR) & $122.1(63.3-174.3)$ \\
\hline & RVESV (mL) (median, IQR) & $92.2(43.0-152.0)$ \\
\hline & RVESVi $\left(\mathrm{mL} / \mathrm{m}^{2}\right)$ (median, IQR) & $54.9(25.7-84.6)$ \\
\hline & RVEF (\%) (median, IQR) & $55.0(45-69.0)$ \\
\hline & RVSV (mL/beat) (median, IQR) & $109.7(6.0-182.5)$ \\
\hline & LVEDV (mL) (median, IQR) & $125.0(69.0-206.5)$ \\
\hline & LVEDVi $\left(\mathrm{mL} / \mathrm{m}^{2}\right)$ (median, IQR) & $75.4(48.8-113.7)$ \\
\hline & LVESV (mL) (median, IQR) & $54.1(27.0-86.0)$ \\
\hline & LVEDVi $\left(\mathrm{mL} / \mathrm{m}^{2}\right)$ (median, IQR) & $33.5(19.9-52.9)$ \\
\hline & LVEF, (\%) (median, IQR) & $57.0(45.5-66.0)$ \\
\hline & LVSV (mL/beat) (median, IQR) & $69.8(42.0-108.3)$ \\
\hline & PR (\%) (median, IQR) & $37.4(27.0-60.0)$ \\
\hline & RVOTO and/or PĀs branches stenosis, n (\%) & $8(9.5)$ \\
\hline
\end{tabular}


Table 1. cont.

\begin{tabular}{|c|c|c|}
\hline \multicolumn{3}{|c|}{ Overall $(N=84)$} \\
\hline \multirow{27}{*}{ CPET values } & Total test duration (s) (median, IQR) & $607(551-724)$ \\
\hline & Peak HR (bpm) (median, IQR) & $176(167-182)$ \\
\hline & Peak HR (\%) (median, IQR) & $88(85-92)$ \\
\hline & HR at AT (bpm) (median, IQR) & $128(119-138)$ \\
\hline & Peak $\mathrm{VO}_{2}(\mathrm{~mL} / \mathrm{min})$ (median, IQR) & $1885(1530-2166)$ \\
\hline & Peak $\mathrm{VO}_{2} / \mathrm{Kg}(\mathrm{mL} / \mathrm{min} / \mathrm{Kg})$ (median, IQR) & $31(25-33)$ \\
\hline & Peak $\mathrm{VO}_{2} / \mathrm{Kg}$ (\% of predicted) (median, IQR) & $68(61-78)$ \\
\hline & $\mathrm{VO}_{2}$ at $\mathrm{AT}(\mathrm{mL} / \mathrm{min} / \mathrm{Kg})($ median, IQR) & $19.7(18.3-23.7)$ \\
\hline & Peak RER (median, IQR) & $1.09(1.02-1.15)$ \\
\hline & Peak $\mathrm{O}_{2}$ pulse (mL/bpm) (median, IQR) & $10.4(8.81 ; 12.28)$ \\
\hline & Peak $\mathrm{O}_{2}$ pulse (\% of predicted) (median, IQR) & $81(71 ; 93)$ \\
\hline & $\mathrm{O}_{2}$ pulse trend $\mathrm{n}(\%)$ & \\
\hline & - Increasing & $7(10.3 \%)$ \\
\hline & - Flattening & $58(85.3 \%)$ \\
\hline & - Decline & $3(4.4 \%)$ \\
\hline & OUES (mL/min/L/min) (median, IQR) & $1908(1665-2538)$ \\
\hline & OUES (\% of predicted) (median, IQR) & $79(68-85)$ \\
\hline & $\mathrm{VE} / \mathrm{VCO}_{2}$ at $\mathrm{AT}$ (median, IQR) & $27.5(25.0-29.9)$ \\
\hline & VE/VCO 2 slope (AT) (median, IQR) & $25.4(23.6-28.9)$ \\
\hline & Peak VE/ $\mathrm{VCO}_{2}$ (median, IQR) & $31.1(27.3-34.3)$ \\
\hline & VE/VCO 2 slope (VCP) (median, IQR) & $28.3(25.5-31.5)$ \\
\hline & VE/ $\mathrm{VCO}_{2}$ slope (stop) (median, IQR) & $30.7(27.5-34.5)$ \\
\hline & FVC (1) (median, IQR) & $3.6(2.97-4.26)$ \\
\hline & FEV1 (1) (median, IQR) & $3.1(2.77-3.79)$ \\
\hline & Peak VE (1/min) (median, IQR) & $61(54-76)$ \\
\hline & Peak VE/ $/ \mathrm{VO}_{2}$ (median, IQR) & $33.0(28.9-38.2)$ \\
\hline & BR (\%) (median, IQR) & $50(40-57)$ \\
\hline
\end{tabular}

Legend: AT: anaerobic threshold; BR: breathing reserve. BSA: Body surface area; HR: heart rate; LVEDV: left ventricular end-diastolic volume; LVEDVi: left ventricular end-diastolic volume indexed to body surface area; LVEF: left ventricular ejection fraction; LVESV: left ventricular end-systolic value; LVESVi: left ventricular endsystolic volume indexed to body surface area; LVSV: left ventricular stroke volume; OUES: oxygen uptake efficiency slope; PR: pulmonary regurgitation; RER: respiratory exchange ratio; RVEDV: right ventricular enddiastolic volume; RVEDVi: right ventricular end-diastolic volume indexed to body surface area; RVEF: right ventricular ejection fraction; RVESV: right ventricular end-systolic volume; RVESVi: right ventricular end-systolic volume indexed to body surface area; RVSV: right ventricular stroke volume; $\mathrm{VE} / \mathrm{VCO}_{2}$ : ventilatory equivalent for $\mathrm{CO}_{2}$; VE: ventilation; $\mathrm{VO}_{2}$ : oxygen consumption.

\subsection{MRI Results}

The main MRI parameters are reported in Table 1 . Twenty (24\%) patients had an RVEDVi $\geq 140 \mathrm{~mL} / \mathrm{m}^{2}$ and 5 patients $(6.0 \%)$ had an RVEDVi $>160 \mathrm{~mL} / \mathrm{m}^{2}$. Depressed RV systolic dysfunction (RV EF $<51 \%$ ) was evident in 28 patients $(33.3 \%)$. Thirty-six patients (43.4\%) had low to moderate PR and 47 patients (56.6\%) had severe PR. Depressed LVEF (i.e., $<55 \%$ ) was reported in 28 patients $(33.3 \%)$. In 16 patients $(19.0 \%)$, the EF of both ventricles was found to be below the cut-off value for normality [30]. However, none of the patients in our cohort had an RVEF $<45 \%$ and only 2 patients had an RVEF of $45 \%$. Similarly, only 3 patients had an LVEF $<50 \%$, but none below $46 \%$.

\subsection{CPET Results}

Table 1 shows the CPET results. The median peak work rate reached was the Bruce protocol phase 4 (IQR $4 ; 4)$. Overall, the median aerobic capacity was decreased in this population (absolute peak $\mathrm{VO}_{2} / \mathrm{Kg} 30 \mathrm{mLO}_{2} / \mathrm{Kg} / \mathrm{min}$ (IQR: 25-33) and peak predicted was 68\% (IQR 61-78)). Exercise testing was maximal in most cases (median peak respiratory exchange ratio (RER): 1.09 (IQR 1.02-1.19), peak heart rate (HR) as a percentage of predicted was 88\% (IQR 85-92)). Median OUES was $1908 \mathrm{~mL} / \mathrm{min} / 1 / \mathrm{min}$ (IQR 1665-2538) with a percentage in respect to predicted values of 79\% (IQR 68-85). Data regarding the $\mathrm{O}_{2}$ pulse trend was available from 68 patients. In $85.3 \%$ of patients, a flattening pattern was observed, whereas, in the remaining, a normal increase in $\mathrm{O}_{2}$ pulse during exercise was seen in $10.3 \%$ and a decline in $4.4 \%$ of patients. Ventilatory response to carbon dioxide $\left(\mathrm{VE} / \mathrm{VCO}_{2}\right)$ was 27.5 (IQR 25.0-29.9) at anaerobic threshold (AT) and 31.1 (IQR 27.3-34.3) at peak exercise, with an overall normal ventilatory efficiency $\left(\mathrm{VE} / \mathrm{VCO}_{2}\right.$ slope of 25.4 (IQR 23.6-28.9) at 
AT and 28.3 (IQR 25.5-31.5) at respiratory compensation (VCP)). Resting oxygen saturation $\left(\mathrm{SpO}_{2}\right)$ was $>95 \%$ in the whole population, with only 2 people $(2.4 \%)$ showing exercise-related desaturation. Among all these parameters, OUES showed a strong positive correlation with peak $\mathrm{VO}_{2}(\mathrm{r}=0.875, p<0.001)$.

\subsection{Adverse Cardiac Events}

The episodes of non-sustained ventricular tachycardia (NS-VT) were observed in seven patients (8.3\%). They were significantly older (30.2 (IQR 15.3-30.8) vs. 22.1 (IQR 15.2-29.8) years, $p=0.014)$, reached a lower peak HR during the stress test (166.9 (IQR 168-181) vs. 174.9 (IQR 167-182.5) bpm, $p=0.045$ ) and had a lower LVEF at MRI (53.6 (IQR $55-60)$ vs. $57.4 \%$ (IQR 54-60), $p=0.035$ ). None of these patients had an RVEF or an LVEF lower than $47 \%$ and $50 \%$ at MRI, respectively.

\subsection{IPAQ Results}

As shown in Figure 1, none of the participants met the higher level of physical activity. Most of the subjects $(58,71.6 \%)$ were classified as "low/inactive", whereas 23 subjects $(28.4 \%)$ were considered as "moderate activity" practitioners. Finally, we did not have the IPAQ result of three patients.

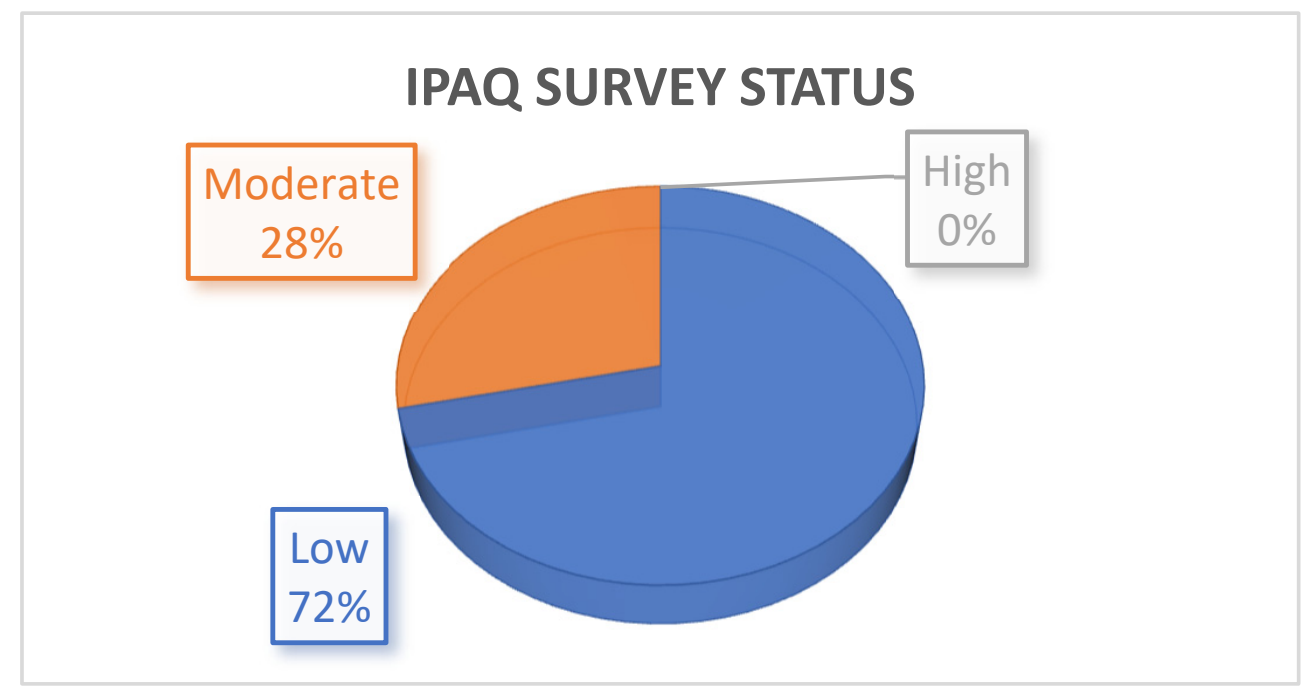

Figure 1. Level of physical activity according to the IPAQ survey.

\subsection{Correlations-CPET and MRI}

On univariate analysis, no correlations were found between CPET parameters and PR, LVEF, or RVEF. RVEDVi was positively correlated with peak $\mathrm{VO}_{2}(p=0.04)$, peak $\mathrm{VO}_{2} / \mathrm{kg}$ $(p=0.005), \mathrm{VO}_{2}$ at AT $(p=0.03)$, and OUES $(p=0.02)$. RVESVi showed a relationship only with OUES $(p=0.04)$. Interestingly, biventricular stroke volumes were significantly correlated with peak $\mathrm{VO}_{2}, \mathrm{OUES}$, and peak $\mathrm{O}_{2}$ pulse ( $p<0.05$ for all). Finally, LVEDVi, as well as RVEDVi, showed a positive correlation with peak $\mathrm{VO}_{2}$, peak $\mathrm{VO}_{2} / \mathrm{kg}, \mathrm{VO}_{2}$ at AT, and OUES ( $p<0.05$ for all), whereas LVESVi correlated only with peak $\mathrm{VO}_{2}(p=0.04)$ and peak $\mathrm{VO}_{2} / \mathrm{kg}(p=0.02)$. However, on multivariate analysis adjusted for age, gender, and level of physical activity, we only found a significant correlation between biventricular stroke volumes and peak $\mathrm{VO}_{2}$, OUES, and peak $\mathrm{O}_{2}$ pulse $(p<0.05$ for all) (Figures 2 and 3). Surprisingly, a relationship between LVEDVi and peak $\mathrm{VO}_{2}$ was also seen (Figure 2).

As noted, 28 patients (33.3\%) had a reduced RVEF: these patients were older (Table 2) and only showed a statistically significant worse RVESVi in respect to people with a normal RVEF (Table 2). Furthermore, no statistically significant differences were found for any CPET parameter. 


\section{PEAK VO2}

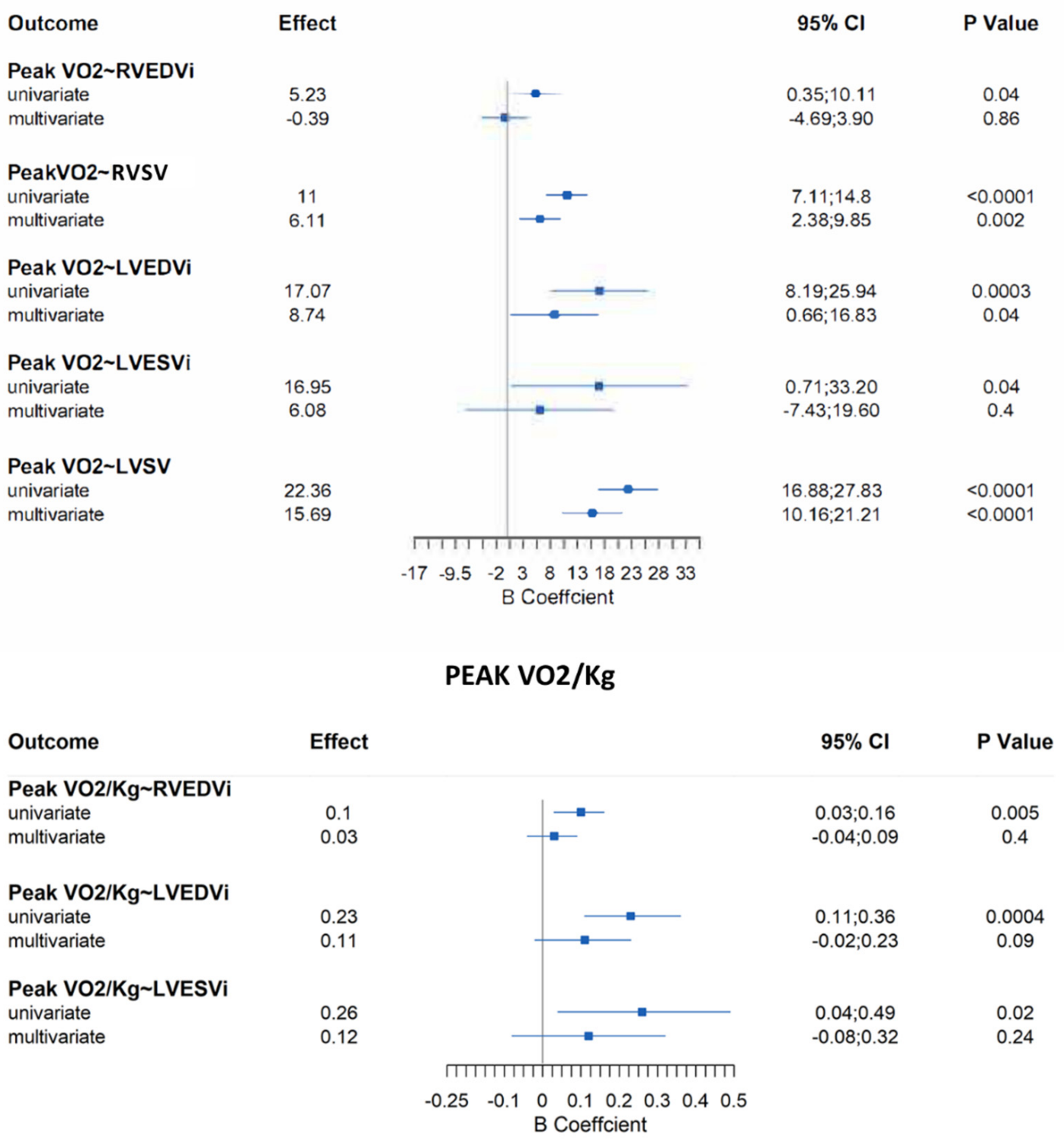

Figure 2. Peak $\mathrm{VO}_{2}$ and peak $\mathrm{VO}_{2} / \mathrm{kg}$ coefficients from univariate and confounder adjusted multivariate regression models (only the statistically significant values are reported in this figure. The other results are in the supplemental materials). Legend: LVEDVi: left ventricular end-diastolic volume indexed to body surface area; LVESVi: left ventricular end-systolic volume indexed to body surface area; LVSV: left ventricular stroke volume; RVEDVi: right ventricular end-diastolic volume indexed to body surface area; RVSV: right ventricular stroke volume.

\subsection{Correlations - IPAQ and CPET/MRI}

On multivariate analysis adjusted for age and gender, no correlation between the IPAQ and MRI parameters was identified. On the contrary, regarding the CPET parameters, a significant correlation between the IPAQ and peak $\mathrm{VO}_{2} / \mathrm{Kg}$ was highlighted on multivariate analysis ( $\beta=0.02,95 \%$ CI 0.003 to $0.04 ; p=0.019)$. On univariate analysis, we documented a statistically significant correlation between the level of physical activity and both peak $\mathrm{HR}(\mathrm{r} 0.25, p=0.011)$ and the indexes of ventilatory efficiency: $\mathrm{VE} / \mathrm{VCO}_{2}$ at AT ( $\mathrm{r} 0.25$, $p=0.015), \mathrm{VE} / \mathrm{VCO}_{2}$ slope at AT (r 0.32, $\left.p=0.003\right)$, and $\mathrm{VE} / \mathrm{VCO}_{2}$ slope at VCP (r 0.30, $p=0.009$ ). On multivariate analysis, no significant correlation between the level of physical activity and the indexes of ventilatory efficiency was found. 


\section{OXYGEN UPTAKE EFFICIENCY SLOPE (OUES)}

$\begin{array}{lc}\text { Outcome } & \text { Effect } \\ \begin{array}{l}\text { OUES RVEDVi } \\ \text { univariate } \\ \text { multivariate }\end{array} & 7.41 \\ \begin{array}{l}\text { OUES RVESVi } \\ \text { univariate } \\ \text { multivariate }\end{array} & 2.15 \\ \begin{array}{l}\text { OUES RVSV } \\ \text { univariate }\end{array} & 10.42 \\ \text { multivariate } & 1.74 \\ \begin{array}{l}\text { OUES LVEDVi } \\ \text { univariate } \\ \text { multivariate }\end{array} & 13.02 \\ \begin{array}{l}\text { OUES LVSV } \\ \text { univariate } \\ \text { multivariate }\end{array} & 18.19 \\ & 9.92 \\ & 26.49 \\ & 17.86\end{array}$

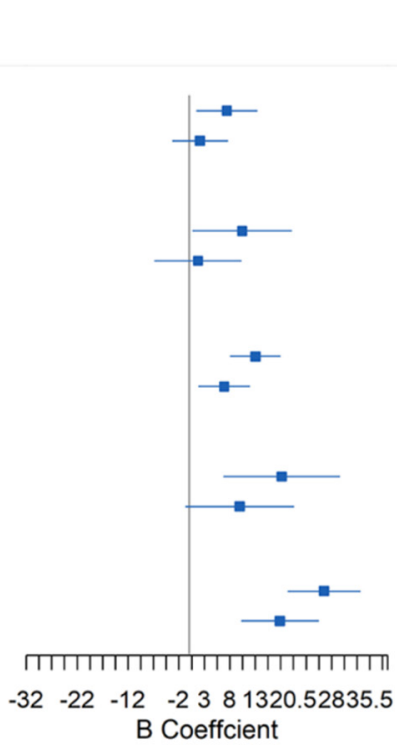

$95 \% \mathrm{Cl}$

$1.50 ; 13.32$

$-3.24 ; 7.54$

$0.72 ; 20.11$

$-6.75 ; 10.23$

$8.13 ; 17.91$

$1.93 ; 11.84$

$6.83 ; 29.55$

$-0.70 ; 20.54$

$19.39 ; 33.60$

$10.31 ; 25.42$

PEAK OXYGEN PULSE

Outcome

Peak_02_pulse RVSV

univariate

multivariate

Peak_02_pulse LVSV

univariate

multivariate

Peak_O2_pulse PR

univariate

multivariate

Effect

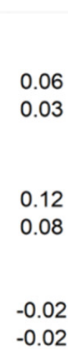

$-0.02$

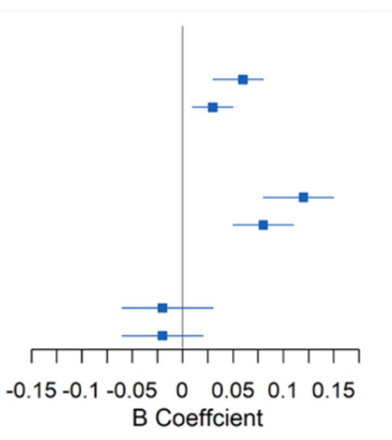

ANAEROBIC THRESHOLD (AT)

Outcome

VO2_AT RVEDVi

univariate

multivariate

VO2_AT LVEDVi

univariate

multivariate

VO2_AT LVESVi

univariate

multivariate
Effect

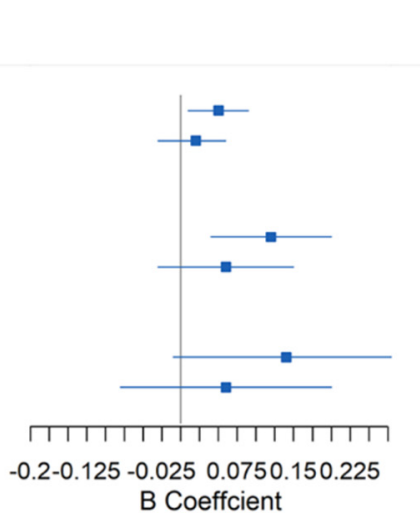

B Coeffcient
P Value

0.02

0.44

0.04

0.69

$<0.0001$

0.008

0.002

0.07

$<0.0001$

$<0.000$
$95 \% \mathrm{Cl} \quad \mathrm{P}$ Value

$\begin{array}{ll}0.01 ; 0.09 & 0.03\end{array}$

$\begin{array}{ll}-0.03 ; 0.06 & 0.5\end{array}$

$0.04 ; 0.20 \quad 0.005$

$\begin{array}{ll}-0.03 ; 0.15 & 0.21\end{array}$

$-0.01 ; 0.28 \quad 0.07$

$\begin{array}{ll}-0.08 ; 0.20 & 0.4\end{array}$

Figure 3. OUES, peak $\mathrm{O}_{2}$ pulse and anaerobic threshold coefficients from univariate and confounder adjusted multivariate regression models (only the statistically significant values are reported in this figure. The other figure with the statistically insignificant correlations is reported in the supplemental material). Legend: LVEDVi: left ventricular end-diastolic volume normalized for body surface area; LVESVi: left ventricular end-systolic volume normalized for body surface area; LVSV: left ventricular stroke volume; RVEDVi: right ventricular end-diastolic volume normalized for body surface area; RVESVi: right ventricular end-systolic volume normalized for body surface area; RVSV: right ventricular stroke volume. 
Table 2. Comparison between rToF patients with normal right ventricular ejection fraction (RVEF) and rToF patients with reduced RVEF for clinical, cardiac magnetic resonance (CMR), and cardiopulmonary exercise testing (CPET) parameters.

\begin{tabular}{|c|c|c|c|}
\hline & $\overline{\text { RVEF } \leq 5}$ & RVEF > 51\% & $p$ Value \\
\hline$n$ & 28 & 56 & \\
\hline age at CPET (mean (SD)) & $26.14(8.85)$ & $21.01(7.61)$ & 0.007 \\
\hline IPAQ (\%) & & & 0.303 \\
\hline 0 & $6(20.7)$ & $20(36.4)$ & \\
\hline 1 & $21(72.4)$ & $33(60.0)$ & \\
\hline 2 & $2(6.9)$ & $2(3.6)$ & \\
\hline male $(\%)$ & $16(55.2)$ & $25(45.5)$ & 0.537 \\
\hline BMI (mean (SD)) & $22.00(2.41)$ & $22.82(4.03)$ & 0.321 \\
\hline RVEDVi (mean (SD)) & $128.50(21.21)$ & $121.46(21.48)$ & 0.155 \\
\hline RVESVi (mean (SD)) & $65.23(11.18)$ & $51.22(11.43)$ & $<0.001$ \\
\hline LVSV (mean (SD)) & 73.05 (16.27) & $72.66(14.50)$ & 0.913 \\
\hline RVSV (mean (SD)) & $106.45(19.02)$ & $116.94(26.13)$ & 0.061 \\
\hline PR (mean (SD)) & $31.97(17.45)$ & $34.45(13.06)$ & 0.463 \\
\hline Peak RER (mean (SD)) & $1.07(0.10)$ & $1.10(0.10)$ & 0.160 \\
\hline $\mathrm{VE} / \mathrm{VCO}_{2}$ slope (stop) (mean (SD)) & $30.74(4.69)$ & $30.68(5.13)$ & 0.958 \\
\hline $\mathrm{VE} / \mathrm{VCO}_{2}$ slope (VCP) (mean (SD)) & $28.52(3.99)$ & $28.94(4.74)$ & 0.724 \\
\hline peak $\mathrm{VE} / \mathrm{VCO}_{2}($ mean $(\mathrm{SD}))$ & $31.01(4.50)$ & $31.32(5.77)$ & 0.806 \\
\hline VE/VCO 2 slope (AT) (mean (SD)) & $25.75(3.47)$ & $26.73(4.44)$ & 0.316 \\
\hline $\mathrm{VE} / \mathrm{VCO}_{2} \mathrm{AT}$ (mean (SD)) & $27.39(3.47)$ & $28.55(4.68)$ & 0.258 \\
\hline OUES (mean (SD)) & $2107.36(579.95)$ & $2083.61(617.28)$ & 0.869 \\
\hline Trend $\mathrm{VO}_{2} \mathrm{HR}$ (mean (SD)) & $1.96(0.36)$ & $1.93(0.39)$ & 0.796 \\
\hline Peak oxygen pulse (mean (SD)) & $11.26(2.64)$ & $10.46(3.20)$ & 0.249 \\
\hline $\mathrm{VO}_{2} \mathrm{AT}$ (mean (SD)) & $21.00(4.23)$ & $21.14(4.41)$ & 0.889 \\
\hline Peak $\mathrm{VO}_{2} / \mathrm{kg}$ (mean (SD)) & $29.61(7.11)$ & $30.42(6.87)$ & 0.612 \\
\hline Peak $\mathrm{VO}_{2}$ (mean (SD)) & $1896.24(458.10)$ & $1884.59(522.23)$ & 0.920 \\
\hline
\end{tabular}

Legend: IPAQ: international physical activity questionnaire; BMI: body mass index; AT: anaerobic threshold RVEDVi: right ventricular end-diastolic volume normalized for body surface area; RVESVi: right ventricular endsystolic volume normalized for body surface area; LVSV: left ventricular stroke volume; RVSV: right ventricular stroke volume; PR: pulmonary regurgitation; RER: respiratory exchange ratio; $\mathrm{VE} / \mathrm{VCO}_{2}$ : ventilatory equivalent for $\mathrm{CO}_{2}$; OUES: oxygen uptake efficiency slope; $\mathrm{VO}_{2}$ : oxygen consumption; $\mathrm{HR}$ : heart rate.

\section{Discussion}

\subsection{Exercise Capacity in the rToF Population and Its Relationship with RV Size and Dysfunction}

Our study highlighted a reduction in exercise tolerance in $\mathrm{rToF}$ patients, although only $6 \%$ of our patients had an RVEF $<47 \%$ (none below $45 \%$ ), $67 \%$ had a preserved RVEF (RVEF $>51 \%$ ) and all had NYHA class I. In particular, a median peak $\mathrm{VO}_{2} / \mathrm{Kg}$ of $30 \mathrm{~mL} / \mathrm{min}$ and a median percentage of predicted peak $\mathrm{VO}_{2}$ of $68 \%$ were found, which are the parameters commonly used to document the patient's cardiovascular status in the rToF population. These data agree with the literature $[17,37,38]$ and, once again, raise the issue of understanding the real state of health of these patients, most of whom report living their lives without any limitations.

The correlation analyses between CPET and cardiac MRI parameters indicated no statistically significant correlation between exercise capacity indexes and PR, RVEF, and LVEF, respectively. These observations are contrary to those previously published $[14,17,18]$. Among the several associations found in this study, the strongest one concerned RV dimensions, particularly RVEDVi, which positively correlated with peak work capacity and submaximal indexes of exercise capacity on univariate analysis. However, on multivariate analysis adjusted for age, gender, and level of physical activity, the correlation between RVEDVi and CPET parameters did not reach statistical significance. This is probably due to the well-known difference in CPET parameters and ventricular size between males and females and/or between adolescents and adults $[11,21]$. The only significant correlations found were between biventricular stroke volumes and LVEDVi when adjusted for age, gender, and level of physical activity. Our findings suggest that in a state of hemodynamic compensation, RV dilation leads to an increase in net pulmonary forward flow, $\mathrm{LV}$ preload, 
and LV volume as an attempt to maintain a similar peak aerobic exercise capacity, reinforcing previously published findings $[17,39]$. Therefore, ToF patients with severe pulmonary insufficiency and RV dilation (within a certain range of RV volumes) are probably able to maintain a satisfactory (albeit not normal) functional capacity within certain limits of the RV dilation and dysfunction [40].

Given our findings that ToF patients with significant pulmonary insufficiency present a clinically acceptable hemodynamic compensation, within certain limits, even those with moderate-severe RV dilatation (i.e., $150 \mathrm{~mL} / \mathrm{m}^{2}$ ), it would be interesting to identify the threshold of RV dilation and dysfunction at which the cardiovascular system begins to fail. Hence, future work should be performed including a significantly higher number of subjects, equally divided among those with mild, moderate, and severe dilation $\left(>160 \mathrm{~mL} / \mathrm{m}^{2}\right)$ and, in the context of dilation, between those with an EF $<$ or $>40 \%$. These data could make important changes to the current guidelines on PVR, highlighting new parameters to be taken into consideration within specific values of RV dilation.

Finally, although our population did not include a sufficient number of patients with an RVEF $<51 \%$ to be able to accurately assess the impact of RV dysfunction on CPET parameters, we have not observed any significant worsening in the above-mentioned parameters in our group of older patients with an RVEF $<51 \%$. This suggests that the worsening of functional capacity could begin to occur in patients with an RVEF < 40\% [18].

\subsection{Effectiveness of OUES as an Index of Exercise Performance in rToF Patients}

Very few data are available on the oxygen uptake efficiency slope (OUES) in the rToF population [21,41], although it has already been demonstrated to be an independent and reproducible measure of cardiorespiratory function that does not require maximal exercise [42]. It has also been proposed to be a valuable prognostic factor in patients with chronic heart failure [43,44], candidates for heart transplant [45] and complex congenital heart disease (Fontan) patients [46]. Our results showed a strong positive correlation between OUES and peak $\mathrm{VO}_{2}(\mathrm{r}=0.875, p<0.001)$, thus proposing OUES as an effective submaximal index of exercise performance even for rToF patients. OUES showed a significant correlation with biventricular stroke volumes and LVEDVi on multivariate analysis, reconfirming that OUES should be considered as an additional parameter to evaluate patients with compensated $\mathrm{rToF}$, even more so in the presence of a test that does not reach an $R E R \geq 1.10$

\subsection{Usefulness of the IPAQ Survey in rToF Patients}

Above all, despite a subjectively reported preserved exercise tolerance (NHYA class I), very few patients (28.4\%) engaged in regular physical activity, and no one in our series reported being engaged in high volumes of physical activity according to the IPAQ survey.

As for the relationship between the IPAQ survey results and both MRI and CPET parameters, we found a significant correlation between the IPAQ and peak $\mathrm{VO}_{2} / \mathrm{Kg}$ on multivariate analysis adjusted for age and gender, reflecting a possible positive effect of even a moderate level of physical activity on exercise capacity in the rToF population. The effectiveness of exercise training on improving peak $\mathrm{VO}_{2} / \mathrm{Kg}$ in cardiovascular diseases is currently well documented, even in CHD [47-51] yet there has been little discussion on prescribing regular physical activity to ToF patients to improve their long-term prognosis.

We believe the significant correlation between the IPAQ and peak $\mathrm{VO}_{2} / \mathrm{Kg}$ observed in our study to be an important result because self-reported methods of assessment such as the IPAQ are cheap and can be easily incorporated into routine clinical practice [52-57] allowing us to obtain additional data about the regular lives of rToF patients. The integration of the data obtained from CPET with the real level of physical activity of these patients based on their IPAQ score could allow us to better understand the clinical status of rToF patients, highlighting even small initial decreases in myocardial reserve in apparently asymptomatic patients. Therefore, future studies on a larger population are needed to better understand the real impact of a given level of physical activity on $\mathrm{VO}_{2}$ values in ToF 
patients, knowing their degree of RV dilation and/or dysfunction. That is to say, a certain $\mathrm{VO}_{2}$ value that is considered normal for a sedentary rToF patient with RV dilation and dysfunction but rather abnormal if the same patient was well-trained. Moreover, it would be essential to conduct further studies, assigning specific physical training protocols to rToF patients appropriate for their health condition, and assess them with MRI. This would allow us to unquestionably evaluate the effective improvement in oxygen consumption with a tailored physical exercise protocol on each patient group divided by RV dilation (e.g., RVEDVi < or $>140 \mathrm{~mL} / \mathrm{m}^{2}$ ) and/or RV dysfunction (e.g., RVEF $<$ or $>47 \%$ ). Such findings would help us to accurately understand the correct type of exercise training to prescribe for each patient to optimize their long-term follow-up. This is because we believe that their behavior in everyday life (regular physical activity and nutrition appropriate to their cardiac condition) is fundamental for obtaining the best results and not just the regular medical checkups they undergo.

Lastly, a longitudinal study on serial changes in CPET parameters, MRI findings and patients' physical activity levels will allow us to take a huge step forward in determining the optimal timing for PVR.

\subsection{Ventricular Arrhythmias in the rToF Population}

In our cohort, VT was noted in a few patients (8.4\%), who presented with LV systolic dysfunction (although no one showed an LVEF $<50 \%$ ), older age, and a lower peak HR reached during CPET (which is typically influenced by age). Considering that we dealt with a population affected by known cardiac issues, it is important to stress that a link between ventricular ectopic beats and age has already been established. Hence, it is not possible to dismiss the fact that these arrhythmic occurrences were at least partially related to the increasing age [58].

\subsection{Study Limitations}

The present study has only included patients with a substantially preserved RVEF, as none had a dysfunction below $45 \%$. Therefore, the lack of correlation between CPET parameters and RV dysfunction could be attributed to this fact. Similarly, only a few patients in our series (5 out of 83,6\%) showed a severe RV dilation (i.e., RVEDVi $>160 \mathrm{~mL} / \mathrm{m}^{2}$ ). A deeper exploration of this subgroup of patients (severely dilated with at least mildly reduced systolic function in NYHA class I) would probably give us more valuable information for an even more accurate prognostic stratification. A small number of patients did not perform a maximal CPET $(8,9.5 \%)$, which could have minimally affected the results. Lastly, our cohort's limited number of patients could be responsible for the lack of a significant correlation between some MRI and CPET parameters.

\subsection{Conclusions}

A reduction in aerobic capacity was observed in our cohort of rToF patients with preserved biventricular function and NYHA class I. The IPAQ (subjective data reported by the patient) associated with CPET (objective data evaluated by the operator) could provide a general picture of the patient's condition. In addition to peak $\mathrm{VO}_{2}, \mathrm{OUES}$ (a submaximal index of exercise tolerance) revealed a strong correlation with exercise performance. Therefore, this parameter could be useful in this population whenever maximal exercise testing is not achievable. The degree of pulmonary insufficiency and severe RV dilation, in the presence of a preserved biventricular function/mild EF reduction, seems to have no importance as long as the compensatory mechanism maintains an adequate stroke volume for a satisfactory functional capacity (even if not normal, when compared with a healthy individual). Currently, there are still no reliable data in the literature that show at which cut-off values of severe RV dilatation and right and/or left ventricular dysfunction this compensation mechanism begins to fail. Therefore, further research is required, including a greater number of patients with $\mathrm{RV}$ dilation $>160 \mathrm{~mL} / \mathrm{m}^{2}$ and with various degrees of right and/or left ventricular dysfunction to resolve this question, which is crucial for 
determining the best timing for PVR. Our work has led us to conclude that CPET is an indispensable tool in the rToF population, although, at times, some parameters are difficult to interpret in the individual patient. Regular physical activity is confirmed to be correlated with better performance concerning both the peak $\mathrm{VO}_{2} / \mathrm{Kg}$. Therefore, a physical activity intervention tailored for each rToF patient could also improve the long-term prognosis in this population.

Author Contributions: Conceptualization, B.L., F.G., M.A.P. and M.B.; data curation, S.S.K., F.S.; formal analysis, L.C.; investigation, B.L., F.G. and M.A.P.; methodology, F.G., F.S., R.M.W., A.S. and A.T.; supervision, R.M.W., V.P., M.G.G., A.P., A.T., L.G., M.A.P., M.B. and F.D.; writing-review and editing, B.L., R.M.W., M.A.P. and M.B. All authors have read and agreed to the published version of the manuscript.

Funding: This research received no external funding.

Institutional Review Board Statement: The study was conducted in accordance with the Declaration of Helsinki, and approved by the Ethics Committee of the Bambino Gesù Children's Hospital IRCCS (Prot. Number 341/2015).

Informed Consent Statement: Informed consent was obtained from all subjects involved in the study.

Data Availability Statement: The data presented in this study are available on request from the corresponding author.

Acknowledgments: No funds provided. The authors sincerely thank Danila Tagliente for collecting the data.

Conflicts of Interest: The authors certify that there are no conflicts of interest with any financial organization regarding the material discussed in the manuscript.

\section{References}

1. Rohit, M.; Rajan, P. Approach to Cyanotic Congenital Heart Disease in Children. Indian J. Pediatr. 2020, 87, 372-380. [CrossRef] [PubMed]

2. Krieger, E.V.; Valente, A.M. Tetralogy of Fallot. Cardiol. Clin. 2020, 38, 365-377. [CrossRef] [PubMed]

3. Diaz-Frias, J.; Guillaume, M. Tetralogy of Fallot; StatPearls: Treasure Island, FL, USA, 2021.

4. Geva, T.; Sandweiss, B.M.; Gauvreau, K.; Lock, J.E.; Powell, A.J. Factors associated with impaired clinical status in long-term survivors of tetralogy of Fallot repair evaluated by magnetic resonance imaging. J. Am. Coll. Cardiol. 2004, 43, 1068-1074. [CrossRef]

5. Frigiola, A.; Hughes, M.; Turner, M.; Taylor, A.; Marek, J.; Giardini, A.; Hsia, T.Y.; Bull, K. Physiological and phenotypic characteristics of late survivors of tetralogy of fallot repair who are free from pulmonary valve replacement. Circulation 2013, 128, 1861-1868. [CrossRef]

6. Knauth, A.L.; Gauvreau, K.; Powell, A.J.; Landzberg, M.J.; Walsh, E.P.; Lock, J.E.; del Nido, P.J.; Geva, T. Ventricular size and function assessed by cardiac MRI predict major adverse clinical outcomes late after tetralogy of Fallot repair. Heart 2008, 94, 211-216. [CrossRef] [PubMed]

7. Leonardi, B.; Calvieri, C.; Perrone, M.A.; Di Rocco, A.; Carotti, A.; Caputo, M.; Secinaro, A.; Curione, D.; Gagliardi, M.G.; Guccione, P.; et al. Risk Factors of Right Ventricular Dysfunction and Adverse Cardiac Events in Patients with Repaired Tetralogy of Fallot. Int. J. Environ. Res. Public Health 2021, 18, 10549. [CrossRef]

8. Ali, L.A.; Gentili, F.; Festa, P.; Perrone, M.A.; Curione, D.; Caputo, M.; Wald, R.; Secinaro, A.; Carotti, A.; Chinali, M.; et al. Long-term assessment of clinical outcomes and disease progression in patients with corrected Tetralogy of Fallot. Eur. Rev. Med. Pharmacol. Sci. 2021, 25, 6300-6310. [CrossRef] [PubMed]

9. Stout, K.K.; Daniels, C.J.; Aboulhosn, J.A.; Bozkurt, B.; Broberg, C.S.; Colman, J.M.; Crumb, S.R.; Dearani, J.A.; Fuller, S.; Gurvitz, M.; et al. 2018 AHA/ACC Guideline for the Management of Adults With Congenital Heart Disease: Executive Summary: A Report of the American College of Cardiology/American Heart Association Task Force on Clinical Practice Guidelines. Circulation 2019, 139, e637-e697. [CrossRef]

10. Samman, A.; Schwerzmann, M.; Balint, O.H.; Tanous, D.; Redington, A.; Granton, J.; Siu, S.C.; Silversides, C.K. Exercise capacity and biventricular function in adult patients with repaired tetralogy of Fallot. Am. Heart J. 2008, 156, 100-105. [CrossRef]

11. Takken, T.; Bongers, B.C.; van Brussel, M.; Haapala, E.A.; Hulzebos, E.H.J. Cardiopulmonary Exercise Testing in Pediatrics. Ann. Am. Thorac. Soc. 2017, 14, S123-S128. [CrossRef]

12. Diller, G.P.; Dimopoulos, K.; Okonko, D.; Li, W.; Babu-Narayan, S.V.; Broberg, C.S.; Johansson, B.; Bouzas, B.; Mullen, M.J.; Poole-Wilson, P.A.; et al. Exercise intolerance in adult congenital heart disease: Comparative severity, correlates, and prognostic implication. Circulation 2005, 112, 828-835. [CrossRef] [PubMed] 
13. Carvalho, J.S.; Shinebourne, E.A.; Busst, C.; Rigby, M.L.; Redington, A.N. Exercise capacity after complete repair of tetralogy of Fallot: Deleterious effects of residual pulmonary regurgitation. Br. Heart J. 1992, 67, 470-473. [CrossRef]

14. Meadows, J.; Powell, A.J.; Geva, T.; Dorfman, A.; Gauvreau, K.; Rhodes, J. Cardiac magnetic resonance imaging correlates of exercise capacity in patients with surgically repaired tetralogy of Fallot. Am. J. Cardiol. 2007, 100, 1446-1450. [CrossRef]

15. Yang, M.C.; Chen, C.A.; Chiu, H.H.; Wang, J.K.; Lin, M.T.; Chiu, S.N.; Lu, C.W.; Huang, S.C.; Wu, M.H. Assessing utility of exercise test in determining exercise prescription in adolescent and adult patients with repaired tetralogy of fallot. Heart Vessels 2017, 32, 201-207. [CrossRef]

16. Babu-Narayan, S.V.; Diller, G.P.; Gheta, R.R.; Bastin, A.J.; Karonis, T.; Li, W.; Pennell, D.J.; Uemura, H.; Sethia, B.; Gatzoulis, M.A.; et al. Clinical outcomes of surgical pulmonary valve replacement after repair of tetralogy of Fallot and potential prognostic value of preoperative cardiopulmonary exercise testing. Circulation 2014, 129, 18-27. [CrossRef] [PubMed]

17. O'Meagher, S.; Munoz, P.A.; Alison, J.A.; Young, I.H.; Tanous, D.J.; Celermajer, D.S.; Puranik, R. Exercise capacity and stroke volume are preserved late after tetralogy repair, despite severe right ventricular dilatation. Heart 2012, 98, 1595-1599. [CrossRef]

18. Rashid, I.; Mahmood, A.; Ismail, T.F.; O’Meagher, S.; Kutty, S.; Celermajer, D.; Puranik, R. Right ventricular systolic dysfunction but not dilatation correlates with prognostically significant reductions in exercise capacity in repaired Tetralogy of Fallot. Eur. Heart J. Cardiovasc. Imaging 2020, 21, 906-913. [CrossRef] [PubMed]

19. Nes, B.M.; Osthus, I.B.; Welde, B.; Aspenes, S.T.; Wisloff, U. Peak oxygen uptake and physical activity in 13- to 18-year-olds: The Young-HUNT study. Med. Sci. Sports Exerc. 2013, 45, 304-313. [CrossRef] [PubMed]

20. Rogowski, M.P.; Guilkey, J.P.; Stephens, B.R.; Cole, A.S.; Mahon, A.D. The influence of maturation on the oxygen uptake efficiency slope. Pediatr. Exerc. Sci. 2012, 24, 347-356. [CrossRef] [PubMed]

21. Dallaire, F.; Wald, R.M.; Marelli, A. The Role of Cardiopulmonary Exercise Testing for Decision Making in Patients with Repaired Tetralogy of Fallot. Pediatr. Cardiol. 2017, 38, 1097-1105. [CrossRef]

22. Tran, D.L.; Maiorana, A.; Davis, G.M.; Celermajer, D.S.; d'Udekem, Y.; Cordina, R. Exercise Testing and Training in Adults With Congenital Heart Disease: A Surgical Perspective. Ann. Thorac. Surg. 2021, 112, 1045-1054. [CrossRef] [PubMed]

23. Tran, D.; Maiorana, A.; Ayer, J.; Lubans, D.R.; Davis, G.M.; Celermajer, D.S.; d’Udekem, Y.; Cordina, R. Recommendations for exercise in adolescents and adults with congenital heart disease. Prog. Cardiovasc. Dis. 2020, 63, 350-366. [CrossRef] [PubMed]

24. Koschate, J.; Cettolo, V.; Hoffmann, U.; Francescato, M.P. Breath-by-breath oxygen uptake during running: Effects of different calculation algorithms. Exp. Physiol. 2019, 104, 1829-1840. [CrossRef] [PubMed]

25. Beaver, W.L.; Lamarra, N.; Wasserman, K. Breath-by-breath measurement of true alveolar gas exchange. J. Appl. Physiol. Respir. Environ. Exerc. Physiol. 1981, 51, 1662-1675. [CrossRef] [PubMed]

26. Hansen, J.E.; Sue, D.Y.; Wasserman, K. Predicted values for clinical exercise testing. Am. Rev. Respir. Dis. 1984, 129, S49-S55. [CrossRef]

27. Cooper, D.M.; Weiler-Ravell, D. Gas exchange response to exercise in children. Am. Rev. Respir. Dis. 1984, 129, S47-S48. [CrossRef]

28. Cooper, D.M.; Leu, S.Y.; Galassetti, P.; Radom-Aizik, S. Dynamic interactions of gas exchange, body mass, and progressive exercise in children. Med. Sci. Sports Exerc. 2014, 46, 877-886. [CrossRef]

29. Leonardi, B.; Secinaro, A.; Calvieri, C.; Perrone, M.A.; Gimigliano, F.; Muscogiuri, G.; Carotti, A.; Drago, F. The role of 3D imaging in the follow-up of patients with repaired tetralogy of Fallot. Eur. Rev. Med. Pharmacol. Sci. 2019, 23, 1698-1709. [CrossRef]

30. Mooij, C.F.; de Wit, C.J.; Graham, D.A.; Powell, A.J.; Geva, T. Reproducibility of MRI measurements of right ventricular size and function in patients with normal and dilated ventricles. J. Magn. Reson. Imaging 2008, 28, 67-73. [CrossRef] [PubMed]

31. Winter, M.M.; Bernink, F.J.; Groenink, M.; Bouma, B.J.; van Dijk, A.P.; Helbing, W.A.; Tijssen, J.G.; Mulder, B.J. Evaluating the systemic right ventricle by CMR: The importance of consistent and reproducible delineation of the cavity. J. Cardiovasc. Magn. Reson. 2008, 10, 40. [CrossRef]

32. Kawel-Boehm, N.; Hetzel, S.J.; Ambale-Venkatesh, B.; Captur, G.; Francois, C.J.; Jerosch-Herold, M.; Salerno, M.; Teague, S.D.; Valsangiacomo-Buechel, E.; van der Geest, R.J.; et al. Reference ranges ("normal values") for cardiovascular magnetic resonance (CMR) in adults and children: 2020 update. J. Cardiovasc. Magn. Reson. 2020, 22, 87. [CrossRef]

33. Valente, A.M.; Geva, T. How to Image Repaired Tetralogy of Fallot. Circ. Cardiovasc. Imaging 2017, 10, e004270. [CrossRef] [PubMed]

34. Harris, M.A.; Avitabile, C.M.; Fu, G.L.; Kim, D.W.; Kim, T.S.; Gillespie, M.J.; Keller, M.S.; Fogel, M.A.; Whitehead, K.K. Accuracy and Internal Consistency of Cardiac Magnetic Resonance Imaging in Measuring Branch Pulmonary Artery Flows in Patients with Conotruncal Anomalies and Branch Pulmonary Artery Stents. Am. J. Cardiol. 2016, 117, 1160-1166. [CrossRef] [PubMed]

35. Craig, C.L.; Marshall, A.L.; Sjostrom, M.; Bauman, A.E.; Booth, M.L.; Ainsworth, B.E.; Pratt, M.; Ekelund, U.; Yngve, A.; Sallis, J.F.; et al. International physical activity questionnaire: 12-country reliability and validity. Med. Sci. Sports Exerc. 2003, 35, 1381-1395. [CrossRef]

36. Muller, J.; Hager, A.; Diller, G.P.; Derrick, G.; Buys, R.; Dubowy, K.O.; Takken, T.; Orwat, S.; Inuzuka, R.; Vanhees, L.; et al. Peak oxygen uptake, ventilatory efficiency and QRS-duration predict event free survival in patients late after surgical repair of tetralogy of Fallot. Int. J. Cardiol. 2015, 196, 158-164. [CrossRef]

37. Kipps, A.K.; Graham, D.A.; Harrild, D.M.; Lewis, E.; Powell, A.J.; Rhodes, J. Longitudinal exercise capacity of patients with repaired tetralogy of fallot. Am. J. Cardiol. 2011, 108, 99-105. [CrossRef] [PubMed] 
38. Giardini, A.; Specchia, S.; Tacy, T.A.; Coutsoumbas, G.; Gargiulo, G.; Donti, A.; Formigari, R.; Bonvicini, M.; Picchio, F.M. Usefulness of cardiopulmonary exercise to predict long-term prognosis in adults with repaired tetralogy of Fallot. Am. J. Cardiol. 2007, 99, 1462-1467. [CrossRef] [PubMed]

39. Yap, J.; Tan, J.L.; Le, T.T.; Gao, F.; Zhong, L.; Liew, R.; Tan, S.Y.; Tan, R.S. Assessment of left ventricular preload by cardiac magnetic resonance imaging predicts exercise capacity in adult operated tetralogy of Fallot: A retrospective study. BMC Cardiovasc. Disord. 2014, 14, 122. [CrossRef]

40. Gnanappa, G.K.; Celermajer, D.S.; Zhu, D.; Puranik, R.; Ayer, J. Severe right ventricular dilatation after repair of Tetralogy of Fallot is associated with increased left ventricular preload and stroke volume. Eur. Heart J. Cardiovasc. Imaging 2019, 20, 1020-1026. [CrossRef]

41. Tsai, Y.J.; Li, M.H.; Tsai, W.J.; Tuan, S.H.; Liao, T.Y.; Lin, K.L. Oxygen uptake efficiency slope and peak oxygen consumption predict prognosis in children with tetralogy of Fallot. Eur. J. Prev. Cardiol. 2016, 23, 1045-1050. [CrossRef]

42. Gavotto, A.; Vandenberghe, D.; Abassi, H.; Huguet, H.; Macioce, V.; Picot, M.C.; Guillaumont, S.; Matecki, S.; Amedro, P. Oxygen uptake efficiency slope: A reliable surrogate parameter for exercise capacity in healthy and cardiac children? Arch. Dis. Child. 2020, 105, 1167-1174. [CrossRef]

43. Myers, J.; Arena, R.; Dewey, F.; Bensimhon, D.; Abella, J.; Hsu, L.; Chase, P.; Guazzi, M.; Peberdy, M.A. A cardiopulmonary exercise testing score for predicting outcomes in patients with heart failure. Am. Heart J. 2008, 156, 1177-1183. [CrossRef]

44. Davies, L.C.; Wensel, R.; Georgiadou, P.; Cicoira, M.; Coats, A.J.; Piepoli, M.F.; Francis, D.P. Enhanced prognostic value from cardiopulmonary exercise testing in chronic heart failure by non-linear analysis: Oxygen uptake efficiency slope. Eur. Heart J. 2006, 27, 684-690. [CrossRef] [PubMed]

45. Pardaens, K.; Van Cleemput, J.; Vanhaecke, J.; Fagard, R.H. Peak oxygen uptake better predicts outcome than submaximal respiratory data in heart transplant candidates. Circulation 2000, 101, 1152-1157. [CrossRef] [PubMed]

46. Chen, C.A.; Chen, S.Y.; Chiu, H.H.; Wang, J.K.; Chang, C.I.; Chiu, I.S.; Chen, Y.S.; Lu, C.W.; Lin, M.T.; Lue, H.C.; et al. Prognostic value of submaximal exercise data for cardiac morbidity in Fontan patients. Med. Sci. Sports Exerc. 2014, 46, 10-15. [CrossRef]

47. Li, X.; Chen, N.; Zhou, X.; Yang, Y.; Chen, S.; Song, Y.; Sun, K.; Du, Q. Exercise Training in Adults With Congenital Heart Disease: A SYSTEMATIC REVIEW AND META-ANALYSIS. J. Cardiopulm. Rehabil. Prev. 2019, 39, 299-307. [CrossRef]

48. Thaulow, E.; Fredriksen, P.M. Exercise and training in adults with congenital heart disease. Int. J. Cardiol. 2004, 97 (Suppl. 1), 35-38. [CrossRef] [PubMed]

49. Shafer, K.M.; Opotowsky, A.R.; Rhodes, J. Exercise testing and spirometry as predictors of mortality in congenital heart disease: Contrasting Fontan physiology with repaired tetralogy of Fallot. Congenit. Heart Dis. 2018, 13, 903-910. [CrossRef]

50. Dua, J.S.; Cooper, A.R.; Fox, K.R.; Graham Stuart, A. Exercise training in adults with congenital heart disease: Feasibility and benefits. Int. J. Cardiol. 2010, 138, 196-205. [CrossRef]

51. Therrien, J.; Fredriksen, P.; Walker, M.; Granton, J.; Reid, G.J.; Webb, G. A pilot study of exercise training in adult patients with repaired tetralogy of Fallot. Can. J. Cardiol. 2003, 19, 685-689.

52. Muller, J.; Amberger, T.; Berg, A.; Goeder, D.; Remmele, J.; Oberhoffer, R.; Ewert, P.; Hager, A. Physical activity in adults with congenital heart disease and associations with functional outcomes. Heart 2017, 103, 1117-1121. [CrossRef] [PubMed]

53. Larsson, L.; Johansson, B.; Wadell, K.; Thilen, U.; Sandberg, C. Adults with congenital heart disease overestimate their physical activity level. Int. J. Cardiol. Heart Vasc. 2019, 22, 13-17. [CrossRef] [PubMed]

54. Gentili, F.; Cafiero, G.; Perrone, M.A.; Bianco, M.; Salvati, A.; Giordano, U.; Silva Kikina, S.; Guccione, P.; De Zorzi, A.; Galletti, L.; et al. The Effects of Physical Inactivity and Exercise at Home in Young Patients with Congenital Heart Disease during the COVID-19 Pandemic. Int. J. Environ. Res. Public Health 2021, 18, 10065. [CrossRef]

55. Perrone, M.A.; Feola, A.; Pieri, M.; Donatucci, B.; Salimei, C.; Lombardo, M.; Perrone, A.; Parisi, A. The Effects of Reduced Physical Activity on the Lipid Profile in Patients with High Cardiovascular Risk during COVID-19 Lockdown. Int. J. Environ. Res. Public Health 2021, 18, 8858. [CrossRef] [PubMed]

56. Perrone, M.; Donatucci, B.; Salvati, A.; Gualtieri, P.; De Lorenzo, A.; Romeo, F.; Bernardini, S. Inflammation, oxidative stress and gene expression: The postprandial approach in professional soccer players to reduce the risk of muscle injuries and early atherosclerosis. Med. Sport 2019, 72, 234-243. [CrossRef]

57. Perrone, M.A.; Santilli, A.; De Zorzi, A.; Turchetta, A.; Bevilacqua, M.; Carotti, A.; Rinelli, G.; Guccione, P. The effects of physical activity in children with hypoplastic left heart syndrome after complete palliation with Fontan procedure. Med. Sport 2020, 73, 526-533. [CrossRef]

58. Sirichand, S.; Killu, A.M.; Padmanabhan, D.; Hodge, D.O.; Chamberlain, A.M.; Brady, P.A.; Kapa, S.; Noseworthy, P.A.; Packer, D.L.; Munger, T.M.; et al. Incidence of Idiopathic Ventricular Arrhythmias: A Population-Based Study. Circ. Arrhythm. Electrophysiol. 2017, 10, e004662. [CrossRef] 